\title{
Behavior Characteristics of Indexing Investment Entities
}

\author{
Lijun Chen ${ }^{13^{*}} \quad$ Yanxi Li ${ }^{1} \quad$ Chenchen Ding ${ }^{1} \quad$ Shaohong Sun ${ }^{2}$ \\ 1.School of Economics and Management, Dalian University of Technology, No. 2 Linggong Road, Dalian \\ 116024, China \\ 2.Dalian Commodity Exchange, No.129 Huizhan Road, Dalian 116023, China \\ 3.China futures Market Monitoring Center, No.5 Financial Street, Beijing 100033, China \\ * E-mail of the corresponding author: chenljdut@163.com
}

\begin{abstract}
Based on the characteristics of investor behavior, this article analyzes the impact of institutional investors and investor sentiment on the liquidity, profitability and stability of the capital market, and analyzes the impact of investor overreaction on the market. Through multiple regression analysis, it is verified that the holding ratio of institutional investors has a significantly negative relationship with the turnover rate of funds, and it has a positive relationship with the annual rate of return of the fund and the annual volatility of the fund. Investor sentiment shows a positive correlation with the turnover rate of funds, the yield of the fund and the volatility of the fund. Through quantile regression, it is found that when the volatility of an index is at a high level, it is more susceptible to the negative impact of the previous trading volume.
\end{abstract}

Keywords: behaviour characteristics, indexing investment, investor sentiment, capital market

DOI: $10.7176 / \mathrm{EJBM} / 13-22-01$

Publication date: November $30^{\text {th }} 2021$

\section{Research on the investor structure of indexing investment}

In the indexing investment market, investors mainly include institutional investors and individual investors. Existing research has proved that the investor structure ratio (mainly refers to the proportion of institutional investors and individual investors) has an important impact on the liquidity, profitability, and risk of investment products.

\subsection{The impact of institutional investors on capital market liquidity}

The most basic factor affecting stock liquidity is market participants. Compared with individual participants, institutional investors have information advantages and scale advantages, which play a vital role in the liquidity level of the stock market. At present, there is no consensus on theoretical research about the impact of institutional shareholding on stock liquidity. Some scholars believe that because institutional investors hold a higher proportion of shares, they are more motivated to supervise companies, improve information disclosure policies, reduce information asymmetry, and increase stock liquidity. Another part of some scholars believes that institutional shareholding has an impact on stock liquidity in terms of information acquisition and trading behavior. On the one hand, institutional investors have a "herding effect" in investment transactions, which increases volatility and reduces stock liquidity. On the other hand, because institutional investors have information advantages, as their shareholding proportion increases, the problem of information asymmetry becomes more serious, which is not conducive to the improvement of stock liquidity.

In addition, different types of institutional investors have different investment characteristics, such as different investment concepts, shareholding ratios, and trading behaviors, which will also have a differentiated impact on stock liquidity. The stocks held by hedge funds (especially leveraged hedge funds) are more sensitive to changes in market liquidity than other institutions or individuals; the huge assets of pension funds reduce transaction costs, and their transactions increase market transparency and reduce information gaps, which improves the liquidity of the stock market. The more institutional investors who have private information are, the smaller the stock market trading volume is and the more investors are inclined to conduct secret transactions. This will not only help reduce its transaction costs, but also have a relatively small impact on the stock market, which is conducive to stock market stability.

\subsection{The impact of institutional investors on the profitability of the capital market}

Many studies have shown that there is a positive correlation between the increase in institutional holdings and the proportion of institutional holdings and the yield in stock seedlings and subsequent periods. At the same time, portfolios with higher institutional holdings also have higher rate of return than those with lower institutional holdings. In addition to the proportion of institutions increasing holdings and keeping holdings, because the number of institutions holding the same stock at the same time is an important form of information transmission between institutions, the number of institutions holding shares and its changes reflect the extent to which many institutions recognize and participate in this stock. In general, most foreign studies believe that institutional 
investors can predict returns to a certain extent and have more information than other market participants.

Domestic empirical research has also reached a similar conclusion: there is a positive correlation between fund holdings and the stock returns of the stock companies it holds. This shows that the fund company has participated in corporate governance, or that the fund holds the company's stock is a piece of good news for the outside world and has a boost to its stock price. In addition, the fund's heavy stocks have strong predictability, and a significantly positive excess return can be obtained by holding a portfolio of forecast stocks.

\subsection{The impact of institutional investors on the stability of the capital market}

Institutional investors have advantages in information collection and processing, transaction costs are significantly lower, and investments based on analysts' follow-up research are more rational, which can play a better role in overseeing listed companies than retail investors, thereby affecting the price synchronization of the invested stocks. Compared with individual investors, institutional investors are more rational, rarely engage in noise trading, and are less affected by market sentiment. Therefore, they can offset the negative effects of individual investors' blind behavior and stabilize the stocks they control.

The introduction of institutional investors is conducive to the stability of the stock market. Institutional investors (money market funds and pension funds) make net purchases during the market decline period and net sales during the market rise period, that is, a negative feedback strategy, which can stabilize the market to a certain extent. The influence of fund behavior on market quality is not only the result of the fund's own investment behavior, but also the constraint of fund holders' behavior. After the Polish pension insurance system reformed in 1999, the increase in pension fund investment activities led to an increase in institutional shareholding. The empirical study of this activity verified that the increase in institutional shareholding temporarily changed the volatility structure of the total return of stocks. Stocks played a stabilizing role. The entry of the Polish Social Security Fund reduced the level of volatility in the Polish stock market, and its purchases and holdings stabilized the stock market.

Institutional investors have obvious advantages in acquiring, processing, using and disseminating information. Compared with individual investors, institutional investors are more informative and wiser. Institutional investors, especially the presence of foreign institutions, can increase the information content of stock prices. Information transmission at the enterprise level is related to geographic location. Institutional investors can use information asymmetry to conduct investment activities. Institutional investors invest in company stocks in close proximity to the geographic location and obtain excess returns. These situations all show that institutional investors are good at mining information for investment, which is conducive to increasing the information content of stock prices and enhancing the effectiveness of the market.

Some researchers believe that institutional investors did not reduce the volatility of the stock market, but aggravated the volatility of the market. Their increase and decrease of positions have the most direct and obvious impact on the stock market. Because institutional investors have a high degree of homogeneity, the market information they pay attention to is often the same, the economic models they use are often similar, and the information processing technology and hedging strategies are also similar. Therefore, herding behavior in trading increases stock price volatility. The ratio of institutional investors in Japan and the United States is relatively high, but institutional investors have played a role in fueling the flames during the previous stock market surges and plunges; during the 2007-2008 financial crisis, institutional investors' seller herd behavior increased the bid-offer spread and liquidity risk. If institutional investors adopt a positive feedback strategy, herding behavior will aggravate stock volatility.

\section{Research on the sentiment of indexing investment entities}

Investor sentiment mainly includes three categories: positive, negative, and neutral. In the capital market, studies have shown that investors tend to be over-confident and over-optimistic. The most typical example is when people make investment decisions, they often show confidence that the investment will succeed. In the indexing investment market, investment decisions of investment entities are also greatly affected by sentiment.

\subsection{The impact of investor sentiment on capital market liquidity}

Under the theory of market efficiency, asset prices depend on their intrinsic value. Even if market pricing is biased, rational arbitrageurs will pull it back to intrinsic value. However, with the development of behavioral finance theory, more and more scholars believe that there are a large number of irrational traders or noisy traders in the market, and the emotions of traders will have a continuous systemic impact on stock prices, and thus asset prices. Not always as predicted by market efficiency theory. Noise traders mainly refer to market trading entities who make decisions based on false subjective beliefs or information that has nothing to do with the company's fundamentals. Contrary to the market efficiency hypothesis, in the real world, noise traders in the market are often affected by market sentiment and their own subjective beliefs (biased perception). Decisions made on this basis often make a large number of traders have a system And long-lasting noise characteristics, and show a long-term 
consistency. However, scholars' research on irrational traders is mainly limited to simplified theoretical descriptions and lacks further follow-up empirical research. In addition, the measurement indicators of investor sentiment often come from the economic intuition of researchers, and the entire market has only one overall aggregate indicator. At present, there is no measurement indicator that can effectively describe the sentiment of individual stocks or portfolio investors.

\subsection{The impact of investor sentiment on the profitability of the capital market}

According to the theory of behavioral finance, the influence of investor sentiment on stock returns is systematic. Therefore, there is a significant relationship between investor sentiment and stock market returns. Research in this area mainly focuses on the ability of investor sentiment to explain the expected return of the stock market, that is, to verify whether investor sentiment can predict the future return of the market through empirical research.

Although some scholars believe that there is no significant correlation between investor sentiment and the future return of the stock market, more researches believe that investor sentiment has the ability to predict future market returns. Foreign scholars have studied the relationship between the sentiment of Wall Street strategists and the return of the S\&P Index, and found that the former has a reverse indicating effect on the latter. In addition, foreign empirical studies have shown that investor sentiment and monthly stock returns in the current period show a significant positive correlation, while there is a significant negative correlation with stock returns in the future for a longer period of time. The negative correlation between investor sentiment and expected return of stocks presents different characteristics in different stock types. Among them, in those small stocks, emerging stocks, high volatility stocks and other types of stocks, investor sentiment and expected return The negative correlation is more obvious. Domestic scholars have also conducted a large number of empirical studies on the relationship between investor sentiment in the Chinese market and stock market returns. The empirical results show that investor sentiment can predict future stock market returns; investor sentiment will affect both current and future returns of the stock market. There is a significant difference between the impact of institutional investor sentiment and individual investor sentiment on stock returns. Among them, institutional investor sentiment will affect stock market returns, but the impact of individual investor sentiment on stock market returns is not obvious.

\subsection{The impact of investor sentiment on the stability of the capital market}

\subsubsection{Measurement of stock market volatility}

Volatility is an important indicator to measure the degree of deviation between asset returns and expected returns, and together with returns constitute the two most important characteristics of asset prices. Whether it is the construction of asset portfolios, the understanding and knowledge of asset price behavior, or the conduct of risk management activities, sufficient knowledge of volatility is required. The volatility of the stock market can be directly used to measure the uncertainty and risk of the stock market, and controlling the uncertainty and risk of the market within an appropriate range is one of the core goals of the healthy and stable operation of the market.

In recent decades, scholars have proposed a series of models and methods to study and characterize volatility, and conducted a large number of empirical studies. In the early days, asset volatility as an important concept mainly appeared in various asset pricing models, such as capital asset pricing models, option pricing models, etc. At this time, the volatility estimate was mainly carried out by calculating the variance. Subsequently, in view of the characteristics of financial time series, scholars proposed various models to characterize volatility characteristics. The most classic volatility models are undoubtedly the ARCH model proposed by Engle (1982) and the GARCH model proposed by Bollerslev (1986), as well as popularization by a large number of scholars on this basis. Among them, the GARCH model is a more general model form that describes the volatility than the ARCH model. Its advantage is that it is more suitable for identifying and estimating the model. Both types of models can be classified as heteroscedastic models, and different models can be applied to different market conditions. For example, the ARCH-M model can be used to describe the relationship between volatility and returns. From the perspective of asset pricing, this is actually an estimate of the risk premium. If the asymmetry of volatility needs to be considered, the classic heteroscedasticity models include the EGARCH model and the TARCH model. In addition, there are the FIGARCH model and FIEGARCH model that can describe the long memory of volatility, and the multivariate GARCH model that can describe the linkage state of volatility among multiple markets, and so on.

In addition to the heteroscedasticity model, another classic volatility model is the stochastic volatility model (SV), which is often used in the research of derivative instruments such as option pricing. This type of model generally assumes that there is an innovation that affects volatility, and that innovation is not necessarily related to the innovation that affects returns, so it is essentially different from the general heteroscedastic model. For different research backgrounds, there are also various extended models for stochastic volatility models, such as commonly used autoregressive stochastic volatility models, threshold autoregressive stochastic volatility models that can describe volatility asymmetry, etc. The estimation of stochastic volatility models is better than GARCH models. It is complicated, but with the development of computer technology and the proposal of optimization 
algorithms, the development of stochastic volatility models has been continuously improved.

In recent years, the characterization of the volatility of high-frequency data has become a hot topic. However, the application of some characteristic heteroscedasticity models and stochastic volatility models of high-frequency data has many limitations. Therefore, scholars have developed research on the volatility of high-frequency data. Method, the realized volatility is a representative method to describe the fluctuation of high-frequency data. One of the advantages of this type of method is that the realized volatility is a parameter-free estimation method, which overcomes the difficulties of estimating other volatility models under high-frequency data, and so on, so it has been widely used.

\subsubsection{The impact of investor sentiment on market volatility}

The above-mentioned research on the volatility of the stock market is either based on the theoretical basis of standard finance, or is a pure description of the stock market volatility from the perspective of a model without considering the internal causes of the volatility. This is useful for understanding stock market volatility. Features are obviously far from enough. Therefore, starting from the theoretical framework of behavioral finance, scholars have begun to pay more and more attention to the impact of investor sentiment on market fluctuations.

In traditional financial theory, asset price fluctuations are determined by basic economic factors and are not affected by factors such as investor behavior. However, there are excessive fluctuations in the financial market that cannot be explained by basic economic factors. Therefore, a large number of scholars have tried to study this issue from the perspective of behavioral finance.

Regarding the impact of investor sentiment on asset price volatility, existing studies basically believe that investor sentiment has a certain explanatory power for stock market volatility, and high sentiment will increase price volatility. The earliest theoretical model is De Long's noise trading model. In this model, investor sentiment will become a systemic risk that affects asset prices, thereby affecting asset price fluctuations. Subsequently, a large number of scholars conducted empirical research on this issue by constructing investor sentiment indicators. Different scholars have constructed proxy indicators of investor sentiment, such as using noise trading behavior, the American Association of Individual Investors Index, and the discount rate of closed-end funds as sentiment. The indicators confirm the ability of investor sentiment to explain fluctuations. Some scholars have discovered through psychological experiments that near the top of asset prices, mood swings and asset prices are mainly determined by changes in economic fundamentals. The two interact and form a feedback loop, which may eventually form a market bubble and cause a market crash.

\section{The impact of investor overreaction on the market}

Overreaction refers to the state of investors in the market showing overreaction to the information of the current period, and this state ultimately causes the stocks that performed particularly well in the previous period to have negative returns in the next period, while the previous period Stocks that perform particularly poorly perform better in the next period. After a series of good news announcements, the company's stock returns in the next period will be less than the company's stocks after a series of bad news announcements. This is because investors have overreacted. After a series of good news announcements, investors became overly optimistic and overreacted, resulting in excessively high stock prices, and then the stock price would gradually fall. Studies have shown that in a portfolio constructed based on the long-term return rate of stocks ( 3 to 5 years), buying stocks that have performed poorly in the past and selling stocks that have performed well in the past will produce excess returns that are higher than the market. This is the reversal effect., This phenomenon also exists in the stock return rate of days or weeks. (See attachment for specific model)

The increase in stock trading volume can be regarded as an improvement in the expected liquidity of stocks, which makes investors have a lower expectation for the future stock yield, which makes the previous trading volume and the current yield have a negative relationship. Trading volume is a good proxy variable for investor sentiment. In a stock market lacking a short-selling mechanism, stocks are easily affected by investor sentiment and deviate from their basic price, and subsequently reverse, leading to a negative relationship between trading volume and yield.

Investor overconfidence, self-attribution bias, and market prosperity are important factors that affect investors' response to information. Most scholars study the relationship between overreaction and transaction volume from the perspective of overconfidence. The empirical test results found that Chinese investors have over-trading behavior caused by over-confidence, and the degree of investor over-confidence weakens with the continuous development of the stock market. In addition, it is also found that the degree of over-trading caused by overconfidence in a bull market is higher than that in a bear market higher. Overreaction increases the trading volume to a certain extent, and the high previous trading volume has a reversal effect on the current stock return, which makes the previous trading volume have a negative adjustment effect on the current return. Therefore, trading volume can be used as a proxy variable for investor overreaction to analyze the impact of previous trading volume on the rate of return, and then analyze the impact of investor overreaction on the index rise and fall. 


\section{Empirical test analysis of indexing investment entities}

On the basis of the above research on the behavior characteristics of investment entities, the OLS method is used to explore the impact of investment entity structure characteristics and emotional performance on indexing investment from the three aspects of liquidity, profitability and stability.

\subsection{Data source}

The research data comes from Wind database and Guotai Junan database. Investor sentiment comes from the CSMAR investor research topic. After excluding missing values, the sample covers 2012 to 2019, with a total of 968 observations. In order to ensure the reliability of the data, this part of the research carried out multi-party verification of the data, and obtained the final data by comparing the same index data of the two databases and taking the average value. STATA15 is used to process the data.

\subsection{Variable definition and data characteristics}

The variable definitions are shown in Table 1. The dependent variables are turnover rate $(T R)$, annual return $(R D)$, annual volatility $(S T D)$, and the independent variables are institutional holding ratio (INS) and investor sentiment $(C O N)$. Table 2 report the descriptive statistics. The annual average turnover rate of the sample indexing products is 0.0311 , the median is 0.009 , and the index data is more left. The annual average yield is $3.86 \%$, and the annual average volatility is 0.143 . In addition, about $42 \%$ of each fund product is held by institutional investors.

\subsection{Multiple regression analysis}

Table 4 reports the results of multiple regression (see attachment). From the perspective of the relationship between institutional holding ratio and fund liquidity, profitability, and stability, the holding ratio of institutional investors and the turnover rate of funds show a significant negative relationship, indicating that the greater the share of fund held by institutional investors, the The liquidity of the fund is lower; the institutional investor's fund holding ratio and the fund's annual return rate show a positive relationship, and it is significant at the $1 \%$ level, indicating that compared with the situation where the institutional holding ratio is small, the higher institutional holding is, the higher the return of proportional funds is. The institutional holding ratio and the annual volatility of the fund show a significant positive relationship, indicating that the higher the fund shares held by institutional investors, the worse the stability of the fund.

From the perspective of the relationship between investor sentiment and fund liquidity, profitability and stability, investor sentiment and fund turnover rate show a significant positive correlation, indicating that when investor sentiment is positive, the liquidity of the fund market is higher. Investor sentiment has a significant positive correlation with fund profitability. Investor sentiment has a positive correlation with fund volatility. When investor sentiment is positive, fund products in the indexing investment market are more volatile.

\subsection{Empirical test analysis of investor overreaction}

This section refers to the above-mentioned related literature, uses the Wind database, selects the transaction volume as a proxy variable for overreaction, uses quantile regression to analyze the impact of the previous transaction volume on the current index, and explores the correction range for the different quantiles of investor overreaction on the next transaction date.

Taking into account the different impacts of overreaction on markets of different sizes, four indexes of Shanghai Stock Exchange All Index (000047), Shanghai 50 Index (000016), Shanghai Mid-Cap Index (000044) and Shanghai Small-Cap Index (000045) are selected for analysis. The Shanghai Stock Exchange All Index Index is an index composed of 500 companies with large, medium and small market capitalization. It can comprehensively reflect the overall performance of large, medium and small-cap companies in the Shanghai Stock Exchange. At the same time, according to the views of Lo and MacKinlay (1990), Connolly and Stivers (2003) and Wang and Cheng (2004), portfolios of different market capitalizations may make the previous stock returns and trading volume have different effects on the current stock returns For a large-scale investment portfolio, we use the Shanghai Stock Exchange 50 Index to represent it. It is composed of the 50 most representative stocks of the Shanghai stock market with large scale and good liquidity, which can comprehensively reflect the Shanghai stock market's most market influence The overall situation of a group of leading companies in China. The mediumsized investment portfolio is represented by the Shanghai Stock Exchange Mid-Cap Index and consists of 130 stocks. The small-scale investment portfolio is represented by the SSE Small Cap Index, which is composed of 500 companies in the SSE All-Share Index and 320 stocks removed. The data of the four stock indexes come from the Wind database, and the time span is from April 3, 2015 to April 3, 2020, including changes in price, trading volume, and closing points.

In order to study the impact of the previous period's trading volume and fluctuations on the current fluctuations, the following model is established using the OLS estimation method: 


$$
\text { Change } e_{t}=a+b L n_{-} d e a l_{t}+\sum_{i} c_{i} \text { Change }_{t-i}+\sum_{j} d L n_{-} \text {dealV } t_{-j}+u_{t}
$$

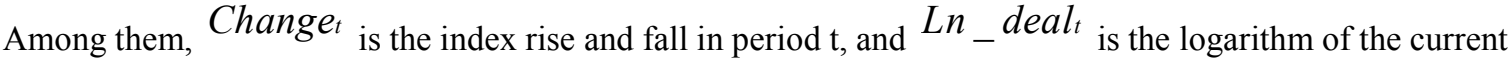
trading volume. The lag of the two is added to study the impact of the previous data on the current period. The above formula is regressed on the lagging fourth-order variables. When the regression is performed, the relevant variables are significant. Therefore, when performing the quantile regression, select the one-lag trading volume and the increase and decrease, and add the current trading volume as the control variable to explore the index increase and decrease under different quantiles. What is the impact of volume and fluctuations? Variable definitions are shown in Table 1.

Descriptive statistics for different indexes are shown in Table 5 and Table 6 (see Appendix). The Shanghai Stock Exchange 50 Index includes companies with larger market capitalization and higher shock resistance. The average value of the five-year increase and decrease is positive, which is higher than that of others. The three indexes $(-0.006 \%,-0.013 \%,-0.019 \%)$ have the smallest standard deviation and high stability. However, the SSE small-cap index includes smaller listed companies, which has poor risk resistance and unstable return.

Its standard deviation reached 1.895, much higher than the other three indexes. The Shanghai Composite Index includes the other three indexes, so its trading volume is significantly higher than the other three. The standard deviation of the Shanghai 50 Index is significantly larger than the other three, indicating that its volatility is relatively high, and its stocks are bought and sold.

\subsection{Statistics and analysis of regression results}

The regression results are shown in Table 7 (see Appendix).

Through the mean regression, it can be found that the current trading volume has a positive and significant impact on the volatility, indicating that the current trading volume has a positive impact on the rise and fall of the stock index, indicating that the increase in trading volume will indeed promote the increase in stock returns. However, the opposite is true for the lagging trading volume, that is, the greater the previous trading volume is, the greater the trading volume declines on current period. When performing quantile regression on the rise and fall, it is found that the current trading volume has a greater heterogeneous effect on different quantiles, and the negative effect on the current high yield is greater. The analysis believes that this reflects that investors' investment behaviors are different in different quantiles of the stock market. When stocks rise sharply, that is, at high quantiles, investors are more inclined to over-trading, leading to their stock yields. In the subsequent reverse adjustment, the correction amplitude is correspondingly larger, and the negative sequence correlation is more obvious. The previous trading volume has a negative effect on the current return rate, which is consistent with Baker and Stein (2004), Amihud and Mendelson (1986) and other viewpoints that the previous trading volume is negatively correlated with the current stock return. From the results of the quantile regression, it can be found that there are differences in the effect of the previous trading volume on the current return rate at different quantile points. From a low yield to a high yield, the impact of the previous trading volume on it gradually increases, indicating that when the stock market rises, investors are more inclined to trade and buy on a large scale; the greater the degree of overreaction, the greater the degree of correction in the subsequent period will be, which makes the negative relationship between stock yield and trading volume more obvious, and the impact on small-cap stocks is much greater than the other three. The negative impact of the previous trading volume on its high quantile point is more strong.

\section{Conclusion}

Through quantile regression, it can be found that when the index rise and fall are at a high level, it is more susceptible to the negative impact of the previous trading volume, that is, the higher the previous trading volume is, the stronger the negative correction degree of the current rise and fall is. If investors' overreaction led to a large number of early investors buying and selling stocks, and the trading volume increased, for the current index rise and fall, the higher the point, the more likely to be affected by investor overconfidence, and the greater the increase, the stronger the impact.

\section{Appendix \\ A1. Investor Overreaction Model}

At present, there are three mainstream models of investor overreaction: BSV, DHS, and HS. Both the BSV model and the DHS model are based on psychological content to model the behavior of investors in the market. The representative bias in the BSV model and the overconfidence in the DHS model play the same role in market behavior. Investors are here Both types of psychology will show overreaction to information. However, the difference is that the BSV model points out that information gradually enters the stock price. When investors first come into contact with new information, they have insufficient response due to conservative deviations, forming a momentum effect in the market. When investors continue to receive good news, investors will show overreaction 
due to representative deviations, which eventually triggers a long-term reversal in the market. The DHS model believes that investors overreacted at the beginning, and the momentum effect afterwards is caused by investors' biased self-attribution under noisy public information. When the final public information arrives, the overreaction of investors will be corrected, and a market reversal will appear. Although the two pointed out similar psychological backgrounds, their views on investors' reactions to new information for the first time were completely different. BSV believes that investors underreact when first exposed to new information, while the DHS model believes that investors overreact when first exposed to new information. HS (Unified Theory Model) is different from the BSV model and the DHS model. It is not based on psychology, but focuses on the mechanism of action of different actors, rather than the cognitive biases of actors. The model divides actors into two categories: "observers" and "momentum traders". Information observers make predictions about the future based on what they observe related to future stock prices. But they can only make predictions based on the information they observe, not the price of the stock. Inertial traders are just the opposite, they can only make predictions based on past prices.

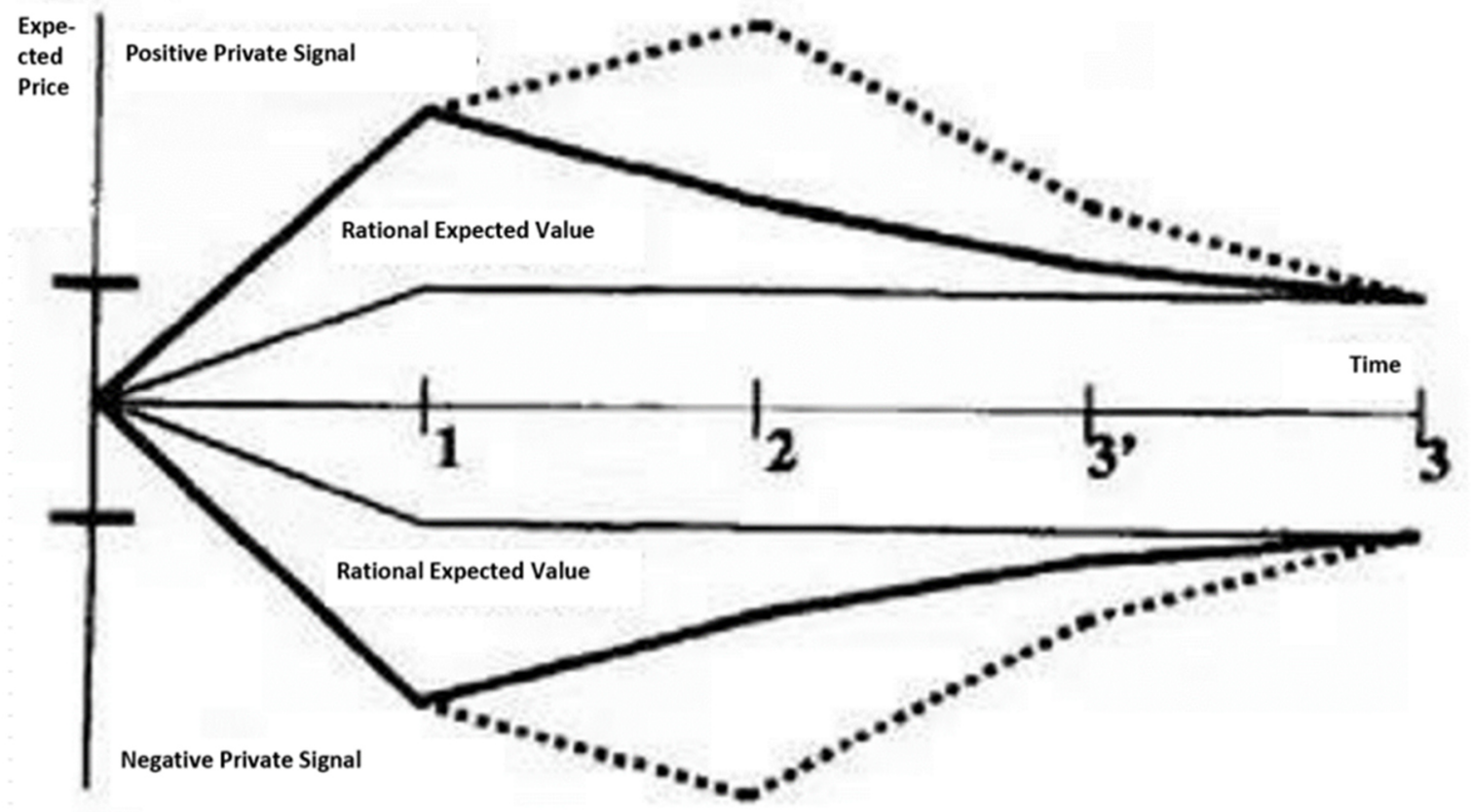

Figure 1. Overreaction and underreaction in the DHS model

Figure 1 shows the two processes of investors' response to private information in the DHS model, which are the expected price route when confidence remains unchanged and the expected price route when confidence changes. The thick solid line represents the expected price route when confidence remains unchanged, and the thin solid line represents price changes when investors are fully rational. At time 1, the insider among investors will get a noisy private message. In the state of overconfidence, investors will overreact to this signal, resulting in stock prices higher than the level that rational investors would reflect. A noisy public signal arrives at time 2 , and this public signal will partially correct the deviated price. At time 3, another noisy public signal arrives, and this noisy public signal continues to correct the deviated price. At time 3, the definite public signal arrives and the overreaction price is completely corrected. The part before time 1 is called the overreaction phase, and the part after that is called the correction phase.

The dotted line represents the expected price route when confidence changes. Studies in psychology have shown that the results of behavior will affect self-confidence, but according to the biased self-attribution theory, individuals will generally attribute correct results to their own abilities, and regard wrong results as caused by external noise, but not a mistake of judgment. Under biased self-attribution, noisy public information has been continuously strengthening investors' confidence, resulting in the continuity of prices in the short term. This trend was not eliminated until the arrival of certain public information. This explanation is different from that the momentum effect of the market in the BSV model is due to insufficient investor response. The explanation for overreaction has always been controversial. Fama and French $(1992,1996)$ pointed out that attractive stocks are actually relatively low-risk, so they will obtain relatively low returns in the future. Scholars began to try to distinguish the two factors of risk and overreaction. La Porta (1996) grouped stocks based on the long-term growth forecasts made by professional analysts. The results showed that analysts would extremely tout their optimistic stocks and feel pessimistic about them. The stocks of is extremely bearish, and the stocks touted by analysts tend to receive negative returns in the next period. On the contrary, stocks that are bearish by analysts will receive positive returns in the next period, which indicates that there is an overreaction in the price. 
Related models of overreaction and underreaction BSV model: The BSV model proposed by Barberis, Shleffer and Vishny (1998) explains the phenomenon of overreaction and underreaction in the market. They believe that there are two paradigms when people make investment decisions: one is representative bias. Under this bias, investors will pay too much attention to the changing patterns of recent data, which leads to insufficient attention to the overall characteristics of the data. Representation deviations form a market reversal phenomenon. The future returns of stocks that have performed well in the past are lower than the future returns of stocks that have performed poorly in the past. The other is conservative bias. Investors cannot modify the increased forecasting model in time according to the changed situation. This deviation is embodied in that the new information in the market cannot be reflected in the stock price at once, but is gradually reflected in the stock price in a considerable period of time. This deviation ultimately leads to insufficient response in the market. Stocks that have performed well in the past will continue to perform well, while stocks that have performed poorly in the past will continue to perform poorly. Starting from these two deviations, the BSV model explains how the investor's decision model causes market price changes to deviate from the efficient market hypothesis. Overreaction and underreaction are two situations in which investors react to market information. When investors involve complex statistical inferences in the investment decision-making process, investors tend to deal with the same problems based on similar situations already stored in their minds instead of strictly following the principles of mathematics and statistics like rational people. It is the dependence on the original model that caused the investor's insufficient response, because it is impossible for investors to adapt to the current situation immediately. When investors continue to receive the same type of information, they will form a typical impression of something in their minds. This typical impression eventually leads to the phenomenon of overreaction when investors face the same type of information but insufficient strength.

\section{A2. Definitions of Variables}

Table 1. Definitions of Variables

\begin{tabular}{|c|c|c|}
\hline Symbols & Variables & Definitions \\
\hline$T R$ & Annual turnover rate & $\begin{array}{l}\qquad \sum_{i=1}^{N}\left(\text { deal }_{i} / \text { ALL }\right) / N \\
N \text { is the symbol of trading days per year, deal } \\
\text { is the symbol of trading volume per day, ALL } \\
\text { is the number of total shares of a fund. }\end{array}$ \\
\hline$R D$ & Annual rate of return & $\begin{array}{l}\text { The annual return of a fund taking into account } \\
\text { the reinvestment of cash dividends }\end{array}$ \\
\hline$S T D$ & Annual volatility & Variance of annual closing price \\
\hline INS & Proportion of institutional holdings & Proportion of institutional investors \\
\hline$C O N$ & Investor sentiment & Investor's confidence \\
\hline SIZE & Size of fund & $\operatorname{Ln}($ market price of fund +1$)$ \\
\hline TIME & Annual trading days & $\operatorname{Ln}($ trading days +1$)$ \\
\hline$D E A L$ & Annual trading volume & Ln(annual tturnover +1$)$ \\
\hline Change & The extent to which the index rose or fell & \\
\hline Ln_deal & Current volume & \\
\hline L1_ln_deal & Trading volume lagged for one period & \\
\hline L1_change & $\begin{array}{l}\text { The extent to which the index rose or fell } \\
\text { lagged for one period }\end{array}$ & \\
\hline
\end{tabular}

\section{A3. Descriptive Statistics}

Table 2. Descriptive Statistics

\begin{tabular}{|l|l|l|l|l|l|l|}
\hline Variables & N & Mean & S.D & Min & Med & Max \\
\hline$T R$ & 968 & 0.0311 & 0.0612 & 0.0002 & 0.009 & 0.442 \\
\hline$R D$ & 968 & 0.0386 & 0.261 & -0.369 & -0.0096 & 0.835 \\
\hline$S T D$ & 968 & 0.143 & 0.180 & 0.003 & 0.0957 & 3.029 \\
\hline$I N S$ & 968 & 0.425 & 0.365 & 0 & 0.331 & 0.993 \\
\hline$C O N$ & 968 & 54.186 & 3.882 & 49.333 & 54.133 & 59.017 \\
\hline$S I Z E$ & 968 & 19.51 & 1.805 & 15.14 & 19.30 & 24.55 \\
\hline$T I M E$ & 968 & 5.292 & 0.434 & 2.398 & 5.485 & 5.505 \\
\hline$D E A L$ & 968 & 19.23 & 2.709 & 12.14 & 19.02 & 27.51 \\
\hline
\end{tabular}

Table 3 lists the results of Person correlation test among variables. The results showed that the correlation coefficients of the key variables were all less than 0.65 . According to the existing studies, there is no serious 
multicollinearity problem in the regression analysis of the above variables.

Table 3. Correlation Analysis

\begin{tabular}{l}
\begin{tabular}{|l|l|l|l|l|l|l|l|}
\hline & $T R$ & $R D$ & $S T D$ & $I N S$ & $C O N$ & SIZE & TIME \\
\hline$T R$ & 1 & & & & & & \\
\hline$R D$ & $0.065^{* *}$ & 1 & & & & & \\
\hline$S T D$ & $0.126^{* * *}$ & $0.213^{* * *}$ & 1 & & & & \\
\hline$I N S$ & $-0.088^{* * *}$ & $0.151^{* * *}$ & $0.212^{* * *}$ & 1 & & & \\
\hline$C O N$ & $0.267^{* * *}$ & $0.641^{* * *}$ & $0.187^{* * *}$ & $0.109^{* * *}$ & 1 & & \\
\hline SIZE & $-0.106^{* * *}$ & $0.143^{* * *}$ & $0.152^{* * *}$ & $0.273^{* * *}$ & $0.064^{* * *}$ & 1 & \\
\hline TIME & $-0.204^{* * *}$ & $0.100^{* * *}$ & $0.180^{* * *}$ & $0.079^{* *}$ & -0.000 & $0.075^{* *}$ & 1 \\
\hline$D E A L$ & $0.336^{* * *}$ & $0.172^{* * *}$ & $0.280^{* * *}$ & $0.273^{* * *}$ & $0.250^{* * *}$ & $0.622^{* * *}$ & $0.095^{* * *}$ \\
\hline
\end{tabular} \\
D $<0.1, * * \mathrm{p}<0.05, * * * \mathrm{p}<0.01$ \\
\hline
\end{tabular}

A4. Multiple regression analysis

Table 4. Multiple regression results

\begin{tabular}{|c|c|c|c|c|c|c|}
\hline & (1) & (2) & (3) & (4) & (5) & (6) \\
\hline & $T R$ & $R D$ & $S T D$ & $T R$ & $R D$ & $S T D$ \\
\hline \multirow{2}{*}{ INS } & $-0.024 * * *$ & $0.037 * *$ & $0.068 * * *$ & $-0.023 * * *$ & $0.043 * *$ & $0.067 * * *$ \\
\hline & $(-6.236)$ & $(2.468)$ & $(5.092)$ & $(-5.954)$ & $(2.501)$ & (4.633) \\
\hline \multirow{2}{*}{$C O N$} & & & & $0.002 * * *$ & $0.047 * * *$ & $0.005 * * *$ \\
\hline & & & & $(5.785)$ & $(27.860)$ & $(3.430)$ \\
\hline \multirow{2}{*}{ SIZE } & $-0.014 * * *$ & $0.012 * * *$ & 0.008 & $-0.016 * * *$ & $0.022 * * *$ & -0.006 \\
\hline & $(-9.484)$ & (3.219) & $(1.609)$ & $(-10.138)$ & $(5.018)$ & $(-1.296)$ \\
\hline \multirow{2}{*}{$D E A L$} & $0.013 * * *$ & $-0.005^{*}$ & $0.006 * * *$ & $0.015 * * *$ & $-0.012 * * *$ & $0.015 * * *$ \\
\hline & $(12.196)$ & $(-1.731)$ & $(3.811)$ & $(12.297)$ & $(-3.907)$ & $(6.985)$ \\
\hline \multirow{2}{*}{ TIME } & $-0.033 * * *$ & $0.038 * * *$ & $0.063 * * *$ & $-0.031 * * *$ & $0.057 * * *$ & $0.069 * * *$ \\
\hline & $(-7.768)$ & $(2.587)$ & $(6.745)$ & $(-7.208)$ & $(4.443)$ & $(6.935)$ \\
\hline \multirow{2}{*}{ Cons } & $0.217 * * *$ & $-0.586 * * *$ & $-0.534 * * *$ & $0.103 * * *$ & $-3.017 * * *$ & $-0.724 * * *$ \\
\hline & $(7.704)$ & $(-6.403)$ & $(-5.077)$ & $(3.620)$ & $(-23.366)$ & $(-5.045)$ \\
\hline Year & Yes & Yes & Yes & No & No & No \\
\hline$N$ & 968 & 968 & 968 & 968 & 968 & 968 \\
\hline$R^{2}$ & 0.409 & 0.626 & 0.276 & 0.362 & 0.492 & 0.133 \\
\hline
\end{tabular}

$\mathrm{t}$ statistics in parentheses

$* \mathrm{p}<0.1, * * \mathrm{p}<0.05, * * * \mathrm{p}<0.01$

Table 5. Descriptive statistics of rise and fall

\begin{tabular}{|l|l|l|l|l|}
\hline Extent of rise and fall & sse all index & sse50 & sse mid-cap & sse small-cap \\
\hline $\mathrm{N}$ & 1220 & 1220 & 1220 & 1220 \\
\hline $\max$ & $6.320 \%$ & $7.840 \%$ & $6.770 \%$ & $7.710 \%$ \\
\hline $\min$ & $-8.800 \%$ & $-9.380 \%$ & $-8.690 \%$ & $-9.030 \%$ \\
\hline mean & $-0.006 \%$ & $0.008 \%$ & $-0.013 \%$ & $-0.019 \%$ \\
\hline std & 1.553 & 1.520 & 1.669 & 1.895 \\
\hline
\end{tabular}

Table 6. Descriptive statistics of trading volume

\begin{tabular}{|l|l|l|l|l|}
\hline Trading volume & sse all index & sse 50 & sse mid-cap & sse small-cap \\
\hline $\mathrm{N}$ & 1220 & 1220 & 1220 & 1220 \\
\hline $\max$ & 15.817 & 15.144 & 14.703 & 14.775 \\
\hline $\min$ & 13.071 & 11.432 & 11.903 & 12.247 \\
\hline mean & 14.111 & 12.734 & 12.961 & 13.240 \\
\hline std & 0.499 & 0.602 & 0.512 & 0.466 \\
\hline
\end{tabular}


Table 7. Quantile regression results

\begin{tabular}{|c|c|c|c|c|c|}
\hline & & sse all index & sse 50 & sse mid-cap & sse small-cap \\
\hline variables & quantile & coefficient & coefficient & coefficient & coefficient \\
\hline \multirow{6}{*}{ Trading volume } & mean & $1.204 * * *$ & $1.173 * * *$ & $1.375 * * *$ & $1.106 * * *$ \\
\hline & $5 \%$ & -1.009 & $0.219 * * *$ & -0.512 & -0.0783 \\
\hline & $25 \%$ & $0.990 * * *$ & $0.653 * * *$ & $1.548 * * *$ & $2.062 * * *$ \\
\hline & $50 \%$ & $1.622 * * *$ & $1.060 * * *$ & $1.885 * * *$ & $3.055^{* * *}$ \\
\hline & $75 \%$ & $3.174 * * *$ & $2.149 * * *$ & $3.112 * * *$ & $4.381 * * *$ \\
\hline & $90 \%$ & $3.596 * * *$ & $2.698 * * *$ & $3.295 * * *$ & $4.477 * * *$ \\
\hline \multirow{6}{*}{$\begin{array}{l}\text { Extent of rise and fall } \\
(-1)\end{array}$} & mean & 0.0257 & 0.0178 & 0.0407 & 0.0551 \\
\hline & $5 \%$ & 0.0677 & -0.00401 & 0.130 & 0.166 \\
\hline & $25 \%$ & -0.0662 & -0.0226 & -0.0203 & 0.0537 \\
\hline & $50 \%$ & -0.0544 & -0.0470 & -0.0759 & -0.0210 \\
\hline & $75 \%$ & -0.157 & $-0.199 *$ & -0.101 & $-0.206^{*}$ \\
\hline & $90 \%$ & $-0.173 * * *$ & $-0.151 * *$ & $-0.137 * *$ & $-0.224 * * *$ \\
\hline \multirow{6}{*}{$\begin{array}{l}\text { Trading volume } \\
(-1)\end{array}$} & mean & $-1.222 * * *$ & $-1.175 * * *$ & $-1.355 * * *$ & $-1.075 * * *$ \\
\hline & $5 \%$ & 0.226 & -0.0926 & -0.364 & -2.128 \\
\hline & $25 \%$ & -0.459 & $-0.304 * *$ & $-1.047 * *$ & $-1.394 *$ \\
\hline & $50 \%$ & $-0.870 * *$ & $-0.479 * *$ & $-0.993 * *$ & $1.760 * *$ \\
\hline & $75 \%$ & $-1.857 * * *$ & $-0.879 * * *$ & $-1.901 * * *$ & $-2.792 * * *$ \\
\hline & $90 \%$ & $-2.422 * * *$ & $-1.659 * * *$ & $-2.154 * * *$ & $-3.018 * * *$ \\
\hline
\end{tabular}

